\title{
Assessing the Data, Models And Tools For Decision-Making: A Case Study of Existing WASH Monitoring and Reporting System in Nepal
}

\author{
Md. Mahidul Islam ${ }^{1}$, Md. Abu Jahid ${ }^{2}$, Mst. Rumana Sharmin ${ }^{3}$ \\ ${ }^{I}$ (IRC Young Professional [Senior Sector Specialist of BRAC WASH Programme, www.brac.net], IRC \\ International Water and Sanitation Centre, The Hague, The Netherlands. www.irc.nl, Social Researcher of SNV \\ The Netherlands Development Cooperation, Water, Sanitation and Hygiene-Resource Centre Network (WASH- \\ RCNN) and Environment and Public Health Organization (ENPHO) in Nepal. And M.Phil Research Fellow, \\ Institute of Education and Research (IER), University of Rajshahi, Bangladesh. \\ ${ }^{2}$ (Senior Lecturer, Department of Business Administration, University of Information Technology and Sciences \\ (UITS), GA - 37/l Pragati Sharani, Baridhara J-Block, Dhaka 1212, , web: www.uits.edu.bd. And M.Phil \\ Research Fellow, Institute of Education and Research (IER), University of Rajshahi, Bangladesh, \\ ${ }^{3}$ (Masters of Science (M.Sc), Geography and Environment Department, Rajshahi College, National University,
}

\begin{abstract}
The government of Nepal has established five Regional Monitoring and Supervision Offices (RMSO) and the National Management Information Project (NMIP, since 2004), for decision-making in Water, Sanitation and Hygiene (WASH) sector. The Nepal has committed to ensuring that a minimum of $53 \%$ of the population will have access to sanitation by 2015 and will achieve 100\% sanitation by 2017 and recent (2011) coverage were $80 \%$ water and $43 \%$ sanitation. The leave of toilet coverage has increased from approximately $6 \%$ in 1990 to $43 \%$ as of 2009/2010, annual growth rate each year's therefore equates $1.9 \%$. If the present trend continues, the toilet coverage will be only $80 \%$ against the national target of $100 \%$ by 2017. It is however rather unclear how this system works in practice for decision making on the basis of present data, models and tools which has been implemented through the existing monitoring and reporting system of RMSO/NMIP. This qualitative study was conducted through participant observation method to assess the gaps between design and practical outcomes of data, models and tools to minimize performance dilemma.
\end{abstract}

Keywords: Decision-making, Information management, Monitoring and Evaluation, and performance dilemma.

\section{INTRODUCTION}

The Department of Water Supply and Sewerage (DWSS) of Nepal has established five Regional Monitoring and Supervision Offices (RMSO) and the National Management Information Project (NMIP, since 2004), in order to monitor, measure and assess the performance of the Water, Sanitation and Hygiene (WASH) programme (NMIP, DWSS 2011). There were approximately, $80 \%$ water and $43 \%$ sanitation coverage in Nepal (NMIP, GoN, MPPW, WSSD and SEIU, May 2011). The government of Nepal has committed to ensuring that a minimum of 53\% of the population will have access to sanitation by 2015 and will achieve $100 \%$ sanitation by 2017 (Sanitation and Hygiene Master Plan 2011). The leave of toilet coverage has increased from approximately $6 \%$ in 1990 to $43 \%$ as of $2009 / 2010$. The annual growth rate of sanitation coverage therefore equates to $1.9 \%$ each year. If the present trend continues, the toilet coverage will be only $80 \%$ against the national target of $100 \%$ by 2017. In addition, a recent UNDP survey reveals that about $65 \%$ of people are living under the poverty line. The National Planning Commission however estimates the figure to be closer to $25.4 \%$. The Nepal sanitation policy does not provide subsidies for the poor and needy to install latrines. Furthermore, 29\% of the populations are landless. It is remarkable fact how policy maker make their plan for progress and sustainable service delivery in this sector. It is however rather unclear how this system works in practice for decision making on the basis of present data, models and tools which has been implemented through the existing Monitoring and Reporting (M\&R) system of RMSO/NMIP. In order to make effective monitoring and reporting system, 'Water Sanitation and Hygiene-Resource Centre Network in Nepal (WASH- RCNN)' and 'The SNV Netherlands Development Cooperation' have intended to conduct an assessment study and accordingly this case study has been carried out. This study focuses on understanding and resolving some of the complexities associated with existing monitoring and reporting system. The study attempts to assess the gaps between design and practical outcomes of this system, and also offer some recommendations for proper decision making and eliminating policy debates at WASH sector in Nepal. 


\section{Conceptual Clarification Of Data, Model And A Tool}

Data are values of qualitative or quantitative variables, belonging to a set of items. Data as an abstract concept can be viewed as the lowest level of abstraction from which information and knowledge are derived A model is a representation of some important aspect of the real world. A tool provides software support that helps create models or other component required in the project (Encyclopedia, 2012).

\section{Relation Between Data, Model And Tools For Decision-Making}

From the Knowledge Management viewpoint, when data is processed to make it useful we call it information, and when information is applied we call it knowledge (Ackoff 1989, Alfonso Segura, J. L. 2010). On the other hand, monitoring system helps through data for improving performance and achieving results towards attaining the specific target for decision-making. However, the data, model and tools are not useful by itself. Reporting is the provision of summarized data of monitoring results for evaluation purposes. So, data, model and tools are generating information and information is generating decisions.

\section{Main Objective of the study}

The main objective of the study is to assess the existing data, model and tools for decision- making at WASH sector in Nepal.

\section{Specific objectives;}

- To know the data, model and tools of existing WASH monitoring and reporting systems in Nepal.

- To know the main gaps between design and function of this system and how this system is utilized for decision making at WASH sector.

- To make recommendations for improving the monitoring and reporting system.

\section{Research Methodology}

The study conducted through qualitative analysis and participant observation method was used to assess data, model and tools of the existing WASH monitoring and reporting system. The researcher was involved empirically for data collection at RMSO office in Surkhet district of mid-western region in Nepal. Mainly, this study was RMSO monitoring and reporting system observation. Secondary sources of data have also used in some cases to explain the monitoring mechanism clarification. The triangulation has accomplished to maintain the validity of research data and also justified by different cross-sectional check with RMSO staffs, however acknowledged limitation of time and unobserved every stage of monitoring and reporting linking mechanism.

\section{The study area}

There are 5 development regions in Nepal. Each region has a RMSO that linked with NMIP and DWSS. It has given emphasis on RMSO at Surkhet district of mid-western region in Nepal. There are 15 districts in mid-western region and all districts are responsible for reporting to RMSO and accordingly to NMIP.

\section{Study Findings}

\section{a. Data maintaining system of existing monitoring and reporting system}

RMSO Engineer and technician are responsible for collecting monitoring and reporting data from field, in some rare cases water consumer groups have also used this activity. They received two days training to conduct social mapping, interviewing, observation and Focus Group Discussion (FGDs) methods. Performance based monitoring and reporting has been used through the existing WASH monitoring and reporting system. RMSO staffs at Surkhet district in mid-western region mentioned that they are collecting both qualitative and quantitative data. The data is being collected and maintained through different formats with formal surveyanalysis. The following Key indicators have been used for the survey;

- Quantity and type of project (piped system, tube-well system, protected spring, dug well, rainwater harvesting, etc.).

- Quantity and type of toilet (water sealed, pit, etc.).

- Functional status of project/scheme.

- Community management system.

Four main formats have been used for data collection from the field; one format on water was sub-divided into three parts (Table1.1). 
Table 1.1: Different types of format and method being used for data collection.

\begin{tabular}{|c|c|c|}
\hline SI.No. & Name of format & Key methods of information collection \\
\hline 1.A & Description of piped water supply system & Social mapping \\
\hline 1.B & Area covered by piped water supply scheme & Social mapping \\
\hline 1.C & $\begin{array}{l}\text { Operational status of completed piped water supply } \\
\text { scheme }\end{array}$ & Interview, FGD and observation \\
\hline 1 & Description of tube well in VDC & Social mapping \\
\hline 2 & VDC profile of drinking water supply & Interview, FGD and observation \\
\hline 3 & VDC profile of sanitation facility & Social mapping and observation \\
\hline
\end{tabular}

(Source: RMSO office at Surkhet, NMIP, 2011)

\section{b. NMIP Data collection tools and model}

A database Management Information System (MIS) was developed in the Oracle platform at NMIP but now using Ms Access software for consolidating data. RMSO is being verified the data then sending Excel soft copies of entire data to the NMIP at Kathmandu. It is using the model as presented in figure;

\subsection{Conceptual framework of data updating and sharing mechanism}

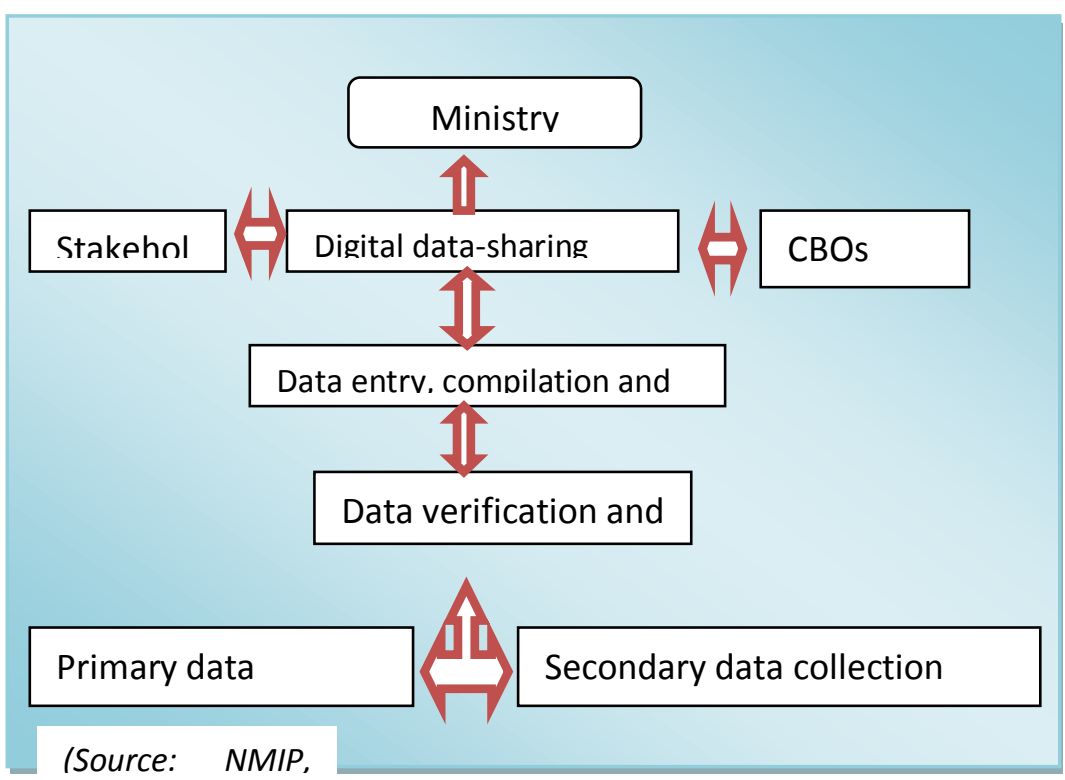

The existing monitoring and reporting data is being collected from two sources; primary and secondary. The collected data verified and approved through RMSO and then send to NMIP for digitalized and sharing to the different stakeholders and concerned ministry. A coding system adopted for administrative units- regions, zones, districts, municipalities and Village Development Committees (VDC) for uploading data at NMIP. It is a single -user data-entry and off-line system. RMSO staff at Surkhet mentioned the data updating regularly but once each fiscal year.

\section{c. Data reporting mechanism at WASH sector in Nepal}

Administrative structure and monitoring data reporting mechanism at WASH sector in Nepal is closely related. Administratively, there are 5 development regions, 14 zones, 75 districts, 58 municipalities, 3,915 Village Development Committees (VDCs). According to sanitation master plan 2011, the linkage diagram of the various committees will be as follows; 
Diagram: 1.2. Data reporting linking mechanism at WASH sector in Nepal.

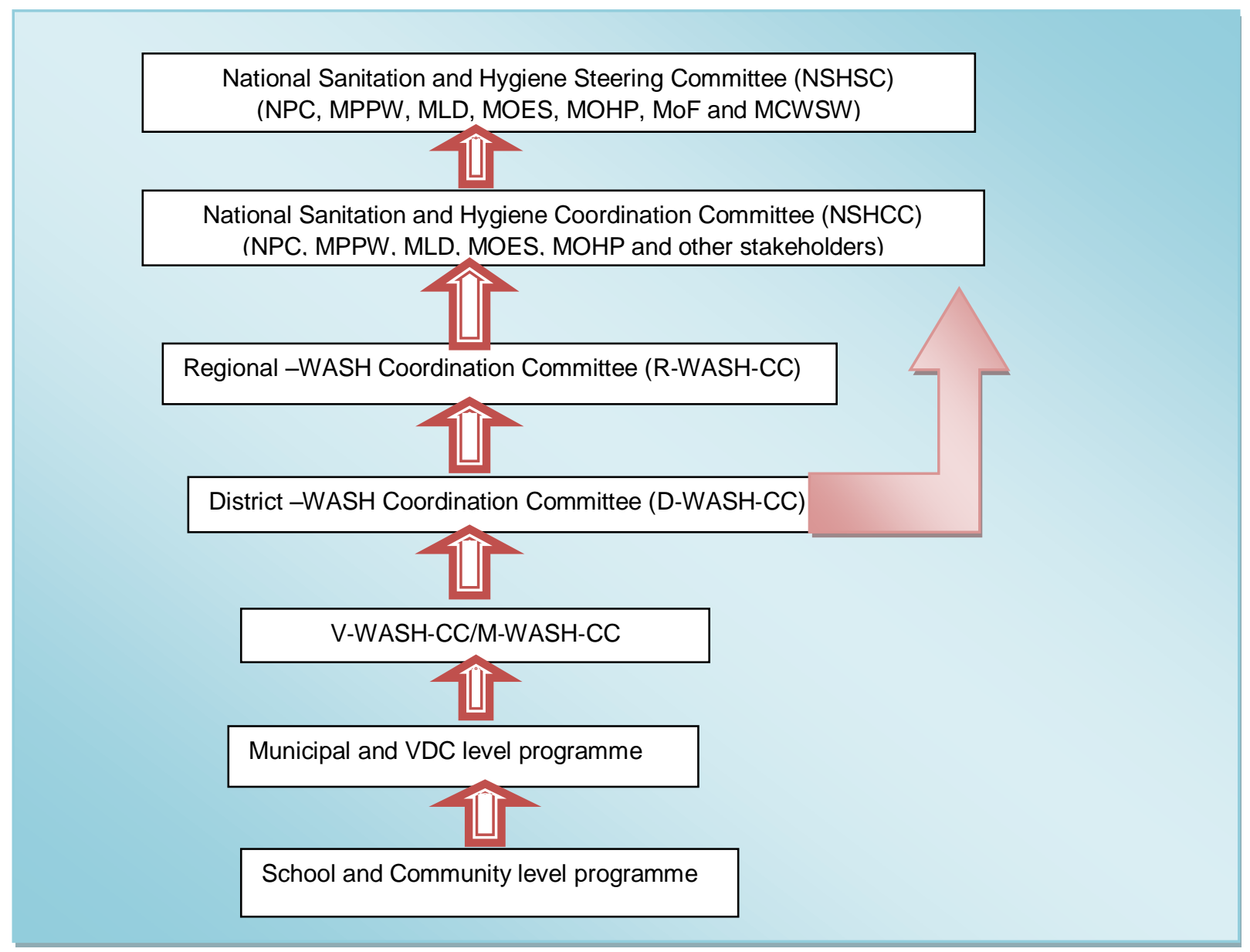

As illustrated in the diagram National Sanitation and Hygiene Steering Committee (NSHSC) will report its activities and progress to the concerned ministries and sector stakeholders as a whole. The NSHSC is back reported by National Sanitation and Hygiene Coordination Committee (NSHCC), Regional Water, Sanitation and Hygiene Coordination Committee (RWASH-CC) and District Water, Sanitation and Hygiene Coordination Committee (D-WASHCC). Similarly, Village Water, Sanitation and Hygiene Coordination Committee (VWASHCC) and Municipality Water, Sanitation and Hygiene Coordination Committee (M-WASHCC) will report their activities and progress to D-WASH-CC. The municipal, VDC, school and community level program will report their program activities and progress to VWASH- CC or M-WASH-CC.

\section{d. Gaps between design and practice of monitoring and reporting system}

\section{i. Data collecting gaps}

$>$ RMSO at Surkhet/NMIP has been receiving data from both primary and secondary sources. Primary sources means that organizations are working locally or involved in implementing WASH activities directly at community level and secondary sources are as donor agencies. The donor agencies are working in sector but indirectly, sometime they are supporting partially to partner organizations. The RMSO/NMIP has been collecting same data from both sources, so automatically there have possibility been double counts. The findings show that local implementing NGOs are sending same data to both donor and RMSO/NMIP, and donor agencies also in some cases sending same data to them.

$>$ Present monitoring and reporting system of RMSO at Surkhet has been using 9 formats with different sections for data collection however NMIP using 6 formats, among them 2 formats have been using for sanitation and others water related areas. The sanitation related format is inappropriate indication to find out sanitation coverage information. The instructions mention if any ward has less than 12 toilets then all households should be observed. If there are more than 12 toilets in a ward but $10 \%$ of the toilets equate to 12 or less than the total number of toilet should be determined to observe on the basis of random sampling that instruction sometime confused to data collector. Because how many latrines exist on the ward that are 
not identified. In addition to that, toilet categories are conflicting in manner in format like the number of dirty, unused, unmanaged, and temporary toilet that make it difficult to categorize by data collectors. Apart from that, how many latrines have been used for 1 household, shared or more that are not mentioned in format. This format has no population control indication but population is increasing and in some areas decreasing due to migration or climate change. The technician of RMSO mentioned that they are facing difficulties to get exact information on sanitation and water through existing formats.

$>$ The different formats and too much questionnaires taking more time to fill up that ${ }_{i}{ }^{\prime} \mathrm{s}$ why respondent feel bored and sometimes did not respond in a timely manner.

$>$ Data collectors are collecting data but did not justify the quality of data or process by external or internal supervisor.

\section{ii. Data processing/presenting gaps}

The monitoring and evaluation data is reported one time in a fiscal year. RMSO staff has explained when mid-term (half of year) evaluation is required; on that time they visited certain areas with the allocated budget of WASH activities, how much money has been spent and so forth. At times allocated money is spent for specific projects but if the project is not complete or has stopped due to climatic or other problems; in those cases the beneficiary did not receive any benefits at that time being calculated with coverage. The provision is to present allocated budget with according to coverage. So, mid-term evaluation is a difficult task for RMSO staff through existing system that refers to decision making is biased in this sector.

\section{iii. Developing Indicator and Survey gaps}

$>$ Repeated questions in the survey are other problems for the data collector and an annoyance for the respondent.

$>$ The system has no option to get hand washing facility, toilet cleaning materials, using sandals, water access at toilet, menstrual hygienic materials, cleaning and so on at household level of hygiene behavior changes indicator or related information.

$>$ The existing system has no selection to get school sanitation and hygiene education programme related information. However, there are many school based WASH programmes implementing at community level.

\section{iv. Project management and follow up gaps}

Lack and sufficient skill manpower is another main problem for proper monitoring and reporting. For example, only 13 staffs at RMSO office at Surkhet (Mid-western region) is responsible for taking over WASH programme activities and at the same time monitoring and reporting.

$>$ NMIP has been using various methods to conduct monitoring and evaluation for primary data collection such as social mapping, interviewing, FGD and observation. RMSO staff mentioned that it is rather unclear how it is possible to manage various methods practice at a same time through limited human resources.

$>$ There is a lack of comprehensive training materials and logistical support to strengthen the data collector.

\section{Situation Analysis For Decision-Making At WASH Sector In Nepal}

The existing monitoring and reporting system for decision making is a key challenge as it is difficult to acquire reliable information through the present data model and tools of RMSO. The findings show that RMSO/NMIP has been using inappropriate many formats for data collection. They have been conducting different methodologies at a same time. Difficulty also being happened when it applied to consolidate data on existing mechanism, and data being double counted in some cases. The study has found some gaps; like data collecting, data use for project management and follow up, processing and presenting, developing indicator and survey and forth at WASH sector in Nepal. As a result, over reporting and under reporting are being reported at WASH sector that influence poor decision making in this sector in Nepal.

For example, the sanitation coverage of Dolpa district in mid-western region was $17.6 \%$ in 2010 (NMIP water and sanitation survey 2010, reported March 2011, table 7; page-20). Steering Committee for National Sanitation Action, Nepal published $46.30 \%$ for this district before one month ago of fiscal year 2010/2011 (page no.7). Sanitation coverage has reported $26.10 \%$ in fiscal year 2009/2010 and 26.22\% in fiscal year 2010/2011 of same district (RMSO at Surkhet, Mid- Western Region Water Supply and Sanitation Coverage Status 2010/2011). WASH Sector Status Report 2011 and its annex 4-A; page 81 has mentioned $18 \%$ sanitation coverage. There is therefore, considerable variation between organizations and reporting authorities which is unmanaged through existing monitoring and reporting system. On the other hand, water coverage is approximately $80 \%$ but most of the water sources are not serving all water users with quality, quantity, accessibility and reliability. However, RMSO/NMIP has been using many formats to collect water related information. Apart from that, WASH in school, financial activities, validity check during monitoring and reporting, appropriate use of different methodologies and formats, lack of accountability and monitoring 
indicator related information are avoided by this system and forth. Decision making is not straightforward if its data, model and tools are not appropriate. Therefore, it is worthwhile to develop data, model and tools of existing monitoring and reporting system.

\section{Conclusion and recommendations}

If we want to explain anything; we need to know the exact data that needs to be explored. This study tried to explore how the data must be reliably replicated through existing monitoring and reporting system under consideration that we have expected. If we practice the wrong system, there can be no such things as appropriate solution for decision- making in WASH sector. So, to get reliable knowledge seeks to improve the existing monitoring and reporting system for decision-making and overcome policy debates. There is therefore, researcher recommended some key points to develop the existing monitoring and reporting system. They are as follows;

\section{Recommendations for specific format to get sanitation coverage data:}

It is an important fact to identify the hygienic latrine according to Joint Monitoring Program (JMP) definition of sanitation. As existing sanitation coverage formats are not appropriate to collect data. So, the recommended format is more flexible to use for sanitation coverage data collection at ward, VDC/municipality, district and region accordingly national level. The suggested format column no.3 indicates for improved sanitation and 4 flexible to be measured as a hygienic latrine according to JMP definition, on the contrary 7 to 10 columns recognizes as unhygienic latrine that will help for further decision making to access sanitation. Population control is another important issue to evaluate programme activities that measured through column 12.

1.2: The recommend format for sanitation related data collection

\begin{tabular}{|c|c|c|c|c|c|c|c|c|c|c|c|c|}
\hline \multirow{4}{*}{$\begin{array}{l}\mathrm{S} \\
1\end{array}$} & \multirow{3}{*}{$\begin{array}{l}\text { Name of } \\
\text { VDC or } \\
\text { Municipal } \\
\text { ity } \\
\text { (Name of } \\
\text { Ward) }\end{array}$} & \multirow{3}{*}{$\begin{array}{c}\text { No. } \\
\text { of } \\
\text { Pres } \\
\text { ent } \\
\text { H/H } \\
\text { s } \\
\text { statu } \\
\text { s }\end{array}$} & \multicolumn{4}{|c|}{ Number of Hygienic Latrine } & \multirow{2}{*}{\multicolumn{2}{|c|}{$\begin{array}{c}\text { Latrines } \\
\text { used more } \\
\text { than two } \\
\mathrm{H} / \mathrm{Hs}\end{array}$}} & \multirow{2}{*}{\multicolumn{2}{|c|}{$\begin{array}{l}\text { Unhygienic } \\
\text { Latrines } \\
\text { Used }\end{array}$}} & \multirow{3}{*}{$\begin{array}{c}\text { Withou } \\
t \\
\text { Latrine } \\
\text { Or } \\
\text { Open } \\
\text { defecat } \\
\text { ed }\end{array}$} & \multirow{3}{*}{$\begin{array}{c}\text { Total } \\
\text { H/Hs } \\
\text { (populati } \\
\text { on } \\
\text { control) }\end{array}$} \\
\hline & & & \multirow{2}{*}{$\begin{array}{l}\text { Individ } \\
\text { ual } \\
\mathrm{H} / \mathrm{Hs} \\
(1 \\
\text { latrine } \\
\text { used } \\
\text { for } 1 \\
\mathrm{H} / \mathrm{Hs}) \\
\end{array}$} & \multirow{2}{*}{$\begin{array}{l}\text { Shared } \\
\mathrm{H} / \mathrm{Hs} \\
(1 \\
\text { latrine } \\
\text { used } \\
\text { for } 2 \\
\mathrm{H} / \mathrm{Hs})\end{array}$} & \multicolumn{2}{|c|}{ Total } & & & & & & \\
\hline & & & & & $\begin{array}{l}\text { No. } \\
\text { of } \\
\mathrm{H} / \mathrm{H} \\
\mathrm{s}\end{array}$ & $\%$ & $\begin{array}{l}\text { No. } \\
\text { of } \\
\text { Latri } \\
\text { ne }\end{array}$ & $\begin{array}{l}\text { No. } \\
\text { of } \\
\mathrm{H} / \mathrm{H} \\
\mathrm{s}\end{array}$ & $\begin{array}{l}\text { No.o } \\
\mathrm{f} \\
\text { latrin } \\
\mathrm{e}\end{array}$ & $\begin{array}{c}\text { No. } \\
\text { of } \\
\mathrm{H} / \mathrm{H} \\
\mathrm{s}\end{array}$ & & \\
\hline & 1 & 2 & 3 & 4 & $\begin{array}{l}5(3 \\
+4) \\
\end{array}$ & 6 & 7 & 8 & 9 & 10 & 11 & $\begin{array}{l}12(5+8+1 \\
0+11)\end{array}$ \\
\hline 1 & & & & & & & & & & & & \\
\hline 2 & & & & & & & & & & & & \\
\hline
\end{tabular}

If we are able to identify precisely what situation belongs to progress then it would be easy to take initiatives regarding who are still uncovered.

$>$ Interactive approach need to verify the data at different level: Interactive means when a data is related to a number of previous data and the relationship between them. This data is gradually cross-checked through revolving mode on way forward from ward to VDC/municipality then district to RMSO and gradually national level. Data validity is needed to cross-cheek during data collection period through triangulation. All implementers will send data to VDC/municipality. They will maintain a register and updated data at least one time per month. VDC/municipality secretary and implementing agency will first cross-check the data then will send district level or accordingly RMSO that should be interactive. Capacity building training is needed for VDC/Municipality secretary and logistical support is important to strengthen this institution. Otherwise, at least it is temporarily needed to recognized that all stakeholders (local programme implementer at community level) will support compulsorily to prepare monitoring and reporting data management activities.

Some specific recommendations are as follows;

$>$ Hygiene behavior change indicator or activities needed to add in present monitoring and reporting system.

For example, hand washing facility, toilet cleaning materials, using sandals, water access at toilet, menstrual hygienic materials, cleaning and so on.

$>$ Institutional activities are needed to attach in present NMIP monitoring and reporting system like WASH in school.

$>$ All meeting, capacity building training, mobilization, coordination, programme activities need to added in present system.

$>$ Financial expenditure also needs to be added in present system because it is the main base to measure coverage on mid-term evaluation. 
$>$ All WASH related activities need to be setup in a same alignment on database Management Information System (MIS)/NMIP. Set up will be a unique code that should present no possibility to mix-up with each other the reporting stages of VDC/municipality, district, region/RMSO or according to reporting loop.

\section{Reference}

[1]. Sanitation and Hygiene Master Plan 2011, Government of Nepal.

[2]. UNDP 2002. "Hand Book on Monitoring and Evaluating for Results. Evaluation Office, United Nations Development Programme, One United Nations Plaza. New York, NY 10017, USA.)

[3]. Mushfiq Mobarak (2011) Evaluation: What, Why and When. WASH Evaluation Workshop II. Bill and Melinda Gates Foundation, Yale University and Abdul Latif Jameel Poverty Action Lab.

[4]. Alfonos, J.L (2010). “Optimization of Monitoring Networks for Water Systems" Information Theory, Value of Information and Public Participation. Dissertation for PhD paper, Delft University of Technology and of the Academic Board of the UNESCO-IHE Institute, Delft, The Netherlands.

[5]. Ajam, T (2011): "Evaluation and Performance Auditing in South Africa; Convergence of reforms" paper at the 4th International Conference on leadership, Governance and Policy in the Public Sector"e, School for Public Management and Administration, University of Pretoria 17-18 February 2011, Pretoria.

[6]. Deirdre Casella (2011). "Monitoring \& Learning for Improvement". Young Professional Workshop,12 October 2011. IRC International Water and Sanitation Centre, The Hauge, The Netherlands.

[7]. National Management Information Project (NMIP), Department of Water Supply and Sewerage (DWSS) final report March 2011. National-wide Coverage and Functionality Status of Water Supply and Sanitation in Nepal. Panipokhari, Kathmandu.

[8]. Water Sanitation and Hygiene (WASH) Sector Status Report May, 2011. Sector Efficiency Improvement Unit. Water Supply and Sanitation Division, Ministry of Physical Planning and Works. Government of Nepal.

[9]. Cole P. Dodgs and Gavin Bennet (2011). Changing Minds. A guide to facilitated participatory planning. International Development Research Centre. Academic Foundation, New Delhi. 